\title{
EDUCACIÓN ESPECIALIZADA
}

SPECIALIZED EDUCATION

\section{NUEVA RURALIDAD Y EDUCACIÓN EN AMÉRICA LATINA RETOS PARA LA FORMACIÓN DOCENTE}

\section{NEW RURALITY AND EDUCATION IN AMERICA LATINA CHALLENGES FOR THE TEACHER TRAINING}

\section{Guillermo Miranda Camacho*}

\author{
RESUMEN
}

Este artículo tiene por objeto analizar algunos de los principales contenidos curriculares, que se deberían tomar en consideración, para los planes de formación de los y las docentes rurales, en el marco del paradigma de la nueva ruralidad y su enfoque territorial en América Latina. La aproximación analítica se realiza desde una visión hermenéutica crítica, examinando la vinculación entre los procesos de cambio estructural que han tenido lugar en el espacio rural de América Latina y las demandas educativas emergentes.

PALABRAS CLAVE: AMÉRICA LATINA * NUEVA RURALIDAD * EDUCACIÓN * EDUCACIÓN RURAL * POLÍTICA EDUCATIVA * POLÍTICA CURRICULAR RURAL * FORMACIÓN DE DOCENTES RURALES

\section{ABSTRACT}

This article has as purpose analyze some of the principal curriculum contents, which should be taken into consideration for plans and training for rural teachers in the context the paradigm of new rurality and territorial focus in Latin America. The analytical approach is made from a critical hermeneutics view, examining the connection between structural change processes that have taken place in rural areas in Latin America and emerging educational demands.

KEYWORDS: LATIN AMERICA * NEW RURALITY *EDUCATION * RURAL EDUCATION * EDUCATIONAL POLICY * RURAL CURRICULUM POLICY * RURAL TEACHER TRAINING

$1 \quad$ Este artículo es un producto parcial del proyecto de investigación Pedagogía Rural hacia el siglo $X X I$, en el que el autor está participando en la División de Educación Rural (DER) del Centro de Investigación y Docencia en Educación (CIDE) de la Universidad Nacional.
* $\quad$ Centro de Investigación y Docencia en Educación (CIDE) de la Universidad Nacional de Costa Rica (UNA). Escuela de Formación Docente de la Universidad de Costa Rica (UCR). gmic1@hotmail.com 


\section{LA EMERGENCIA DE LA NUEVA RURALIDAD}

La nueva ruralidad, como concepto, representa una nueva visión del espacio rural y por consiguiente, una reinterpretación del desarrollo rural basada en los acelerados y profundos cambios en este mundo. Con este concepto se denomina la naciente visión del espacio rural y la nueva forma de concebir el desarrollo rural. Se trata de un fenómeno emergente, tanto en Europa como en América Latina, producido por los cambios estructurales del capitalismo global. La intensidad y difusión del cambio rural en las últimas cinco décadas que observan Pérez y Caballero (2003), han sido mucho mayores en los países de Europa latina que en los de América Latina. La explicación de este proceso la atribuyen al mayor desarrollo económico general de los países europeos, que integran el desarrollo rural como parte fundamental del desarrollo general. A este respecto, señalan que tres circunstancias impulsaron el cambio rural en la Europa latina: 1. la fuerte demanda de mano de obra en empleos industriales $y$ de servicios de alta productividad, que favoreció la migración y la diversificación de la ocupación rural; 2. un bajo crecimiento demográfico que, sumado a lo anterior, impidió la formación de excedentes de mano de obra rural y 3 . una fuerte disponibilidad de recursos para la inversión que permitió el empleo de cuantiosas sumas en la modernización del medio rural ${ }^{2}$.

Este conjunto de circunstancias propiciaron procesos de desarrollo endógeno en muchas zonas rurales, que fueron apoyadas por una generosa política de la Unión Europea, encaminada a la modernización de las regiones menos favorecidas. Para su puesta en marcha, se otorgaron fondos estructurales con un decidido apoyo de una política agrícola común que permitió aumentar la producción y el ingreso de los agricultores, aunque a costa de un gran esfuerzo presupuestario y la distorsión de los mercados agrícolas.

2 Ceña define el medio rural como: “... el conjunto de regiones o zonas con actividades diversas (agricultura, industrias pequeñas y medianas, comercio, servicios) y en las que se asientan pueblos, aldeas, pequeñas ciudades y centros regionales, espacios naturales y cultivados..." (1993: 29).
Entre los nuevos aspectos que gravitan alrededor de esta nueva concepción de la ruralidad en América Latina coincidentes con los de Europa, Pérez y Caballero destacan:

a) la acentuación en la dimensión territorial sobre la sectorial agraria,

b) reconocimiento de las vinculaciones entre pequeñas ciudades $y$ el medio rural circundante,

c) la articulación estructural entre el desarrollo urbano y el rural,

d) el carácter complementario entre la actividad agrícola y otras ocupaciones en la generación de ingresos, de la generalización de la agricultura a tiempo parcial y el origen multisectorial del ingreso familiar en el medio rural,

e) incremento de la función residencial en las zonas rurales, con el concomitante aumento de la demanda de servicios sociales $y$ residenciales que contrasta con la percepción productiva o recreativa,

f) aumento del potencial económico de activos ligados al territorio de tipo geográfico, histórico, cultural, paisajístico y ecológico,

g) acento en la participación de los diversos agentes involucrados en el diseño y la aplicación de las políticas y programas de desarrollo rural (2003:11-12).

Las administraciones públicas no han sido plenamente reorganizadas para diseñar y operar políticas con lógica territorial, no obstante, las políticas aplicadas en las zonas rurales en ambos continentes, obedecen todavía más a lógicas sectoriales. En Europa, por ejemplo, los programas de tipo territorial tienen recursos minoritarios dentro la Política de Desarrollo Rural, que constituye el segundo pilar de la Política Agrícola Común de la Unión Europea (PAC). La tendencia es al aumento de los recursos destinados a los programas territoriales en virtud de que la agricultura europea está enfrentando nuevos retos derivados de la globalización, de manera particular, por lo cambios en el comercio mundial, las mayores 
exigencias de calidad de los consumidores y la ampliación de la Unión Europea.

Esto obedece a un complejo conjunto de factores que gravitan alrededor de la definición del desarrollo sostenible rural como el principio fundamental que sustenta toda la política rural en el futuro inmediato. Los objetivos prioritarios de la Unión Europea son de orientación social, tales como: invertir el proceso de emigración del campo, combatir la pobreza, fomentar el empleo y la igualdad de oportunidades, responder a la creciente demanda de calidad de vida y mejorar el bienestar de las comunidades rurales. Todos estos aspectos quedaron establecidos en la Declaración de Cork (Irlanda, 1996) y la Agenda 2000 (Berlín, 1999) teniendo como eje la génesis de una política comunitaria de desarrollo rural.

Todos estos aspectos ponen en evidencia el desplazamiento hacia el enfoque territorial del desarrollo rural asumido por los organismos internacionales de desarrollo y los medios académicos universitarios.

\section{EL CONCEPTO DE NUEVA RURALIDAD Y EL ENFOQUE TERRITORIAL}

En América Latina, la pobreza rural y la dicotomía entre agricultura empresarial y campesina influye en el concepto de desarrollo rural, vinculándolo a la agricultura campesina y a la lucha contra la pobreza en las regiones rurales. Caso contrario, en Europa, el desarrollo rural está supeditado a la lucha contra la marginación de ciertas regiones, el uso más racional de los territorios nacionales evitando que queden despoblados y el interés de mantener vivas las culturas, tradiciones y patrimonios para compartirlos con fines turísticos. Trejos señala que un conjunto de factores han dado lugar al enfoque denominado "nueva ruralidad". Este conjunto de factores han dibujado el nuevo escenario rural en las Américas, en el cual la globalización y los cambios sociales, económicos, culturales y políticos, que han tenido lugar en el contexto nacional e internacional, han afectado la agricultura, el medio rural y el desarrollo humano de las comunidades asentadas en sus territorios. Problemas como la pobreza rural y el incremento de los desequilibrios regionales, las amenazas a los ecosistemas y la gobernabilidad de los sistemas políticos, son factores que han llevado a revalorar lo rural desde la perspectiva del territorio $y$ de las múltiples interrelaciones que tienen lugar en otras dimensiones, por ejemplo, las actividades agrícolas y no agrícolas, entre lo rural y lo urbano, entre lo social, lo económico y lo ecológico (Trejos, 2000: 16).

Por otra parte, los cambios en el medio rural han puesto de relieve, en las últimas décadas, un incremento notable de los ingresos generados por las distintas actividades no agrícolas prediales $y$ extraprediales de las familias campesinas. Los cambios se pusieron de manifiesto en aspectos tales como:

$\diamond \quad$ Un mayor dinamismo e importancia creciente de las actividades rurales no agrícolas, en relación con la generación de empleos y los ingresos. A comienzos de la década de 1980, el ingreso no rural era de un $25 \%$ a $30 \%$ del total del ingreso rural, ya en la segunda mitad de la década de 1990, el porcentaje se eleva a un 40\% en América Latina.

$\diamond \quad$ Otro indicador importante de este proceso es el peso mayor del empleo dedicado a estas actividades que recaía en las mujeres y no en los hombres. Los datos sobre empleo presentan una variación entre un $65 \%$ a un $90 \%$ en las mujeres $y$ entre un $20 \%$ a un $25 \%$ en los hombres, en los diferentes países de América Latina.

$\diamond \quad$ La participación de la mujer en actividades de servicio fue de un 51\%; en comercio, hotelería y restaurantes un 53\% y en manufactura un $43 \%$.

$\diamond \quad$ Según las estimaciones de fines del decenio de 1990, un 39\% de la población rural latinoamericana ocupada en actividades no agrícolas, dedicada a servicios sociales, comunales y personales alcanzó un 36\%; el comercio, los hoteles y los restaurantes un $25 \%$ y la manufactura un $21 \%$.

$\diamond \quad$ Estas actividades, en efecto, fueron más productivas que las agropecuarias 
$y$ produjeron ingresos superiores (datos tomados de Kay, 2007: 85-86).

El empleo rural no agrícola tiene una significación diferente para las familias campesinas pobres $y$ ricas, de acuerdo con su nivel de ingreso (Kay, 2007). Para las familias campesinas pobres, constituye un mecanismo para mantener su acceso a un pedazo de tierra $y$ subsistir; mientras que para las ricas son una forma de acumular capital mediante inversiones en compra e inversiones que aumenten la productividad de la tierra: fertilizantes, pesticidas y mano de obra, maquinaria e instrumentos de trabajo. Asimismo, es utilizada para invertir en capital humano financiando la educación de sus hijos e hijas. Los campesinos pobres, señala Kay, dependen en mayor grado de ingreso no agropecuario que los campesinos ricos; comparativamente, el monto del ingreso es ostensiblemente menor en las familias pobres que en las ricas (2007: 85). Como lo pone de relieve un informe de la CEPAL sobre la pobreza rural (Tejo, 2000: 23), este proceso está estrechamente vinculado a un ostensible cambio en el desarrollo de las actividades no agrícolas del espacio rural. En este informe, se destaca el aumento de la participación de las personas dedicadas a actividades diferentes a las del agro y un notable incremento de empleo más acelerado, que incluso el empleo agrícola, lo que cambia el panorama de las poblaciones rurales. La realidad pone de manifiesto, asimismo, que el dinamismo económico no solo se ha concentrado en las áreas urbanas sino además en las áreas rurales.

El Instituto Interamericano de Ciencias Agrícolas (IICA) incorporó el concepto de "espacios rurales" como un escenario sociopolítico propicio para focalizar eficientemente la asignación de recursos, en virtud de ser el escenario donde se articulan las relaciones sociales y económicas. Espacio, en el que a la vez, tiene lugar un desarrollo sostenible definido como:

... el proceso de transformación de las sociedades rurales y sus unidades territoriales, centrado en las personas, participativo, con políticas específicas dirigidas a la superación de los desequilibrios sociales, económicos, institucionales, ecológicos y de género, que busca ampliar las oportunidades de género (IICA, 2000).

Complementariamente, el IICA propone en la conceptualización de la nueva ruralidad, la incorporación de la visión territorial en aspectos tales como: los procesos de adopción de decisiones, formulación de políticas, planificación y gestión del desarrollo. En la visión de este organismo interamericano las unidades territoriales incluyen, entre otras, unidades territoriales diversas: cuencas hidrográficas, humedales y zonas marino-costeras, unidades político-administrativas locales, regiones fronterizas, ecosistemas frágiles, áreas protegidas y corredores biológicos (2000: 12). Según esta visión, el desarrollo rural debe centrarse en el desarrollo humano que, al mismo tiempo, debe ser sostenible. Pero además, como explica Trejos (2000: 20) el crecimiento económico debe responder al principio de equidad social, superando el enfoque compensatorio $y$ asistencial del desarrollo rural y el capital social como estrategias de desarrollo.

La apreciación de las transformaciones en el medio rural y su significación teórica, programática y práctica, resultante de una reflexión analítica de los estudiosos del campo $y$ de los organismos internacionales (BID, Banco Mundial, IICA, CEPAL, FAO, etc.) ha arribado al reconocimiento de una realidad social, económica, política y cultural en los espacios geográficos rurales muy diferentes a los contemplados en los modelos teóricos del desarrollo rural anteriores, que no daban cuenta de esas transformaciones. El advenimiento del capitalismo global ha constituido el gran marco de referencia que produce este proceso de cambio estructural. Llambí y Pérez (2007: 54) observan que el acelerado proceso de cambio en los territorios rurales, ha exigido a los especialistas una nueva teorización de espacio rural, desde la visión del desarrollo rural trascendiendo su dimensión físico-natural al integrar en el concepto de territorio los cambios estructurales sociales, culturales, económicos y políticos. Al mismo 
tiempo, observan que el territorio es además, de una categoría analítica u operativa, una construcción social según la perspectiva normativa o cognitiva de quienes en él habitan y de sus poblaciones circundantes. Como construcción social, el territorio, por lo tanto, está generalmente vinculado al diseño e implementación de proyectos desde la base por los propios actores sociales.

La riqueza de la estructura rural — como lo expresa por su parte Lucy $\mathrm{Niño}^{3}$ — radica en su cultura, tradiciones, valores e instituciones. Manifiesta que no hay que desconocer la potencialidad de la nueva ruralidad, por lo que se deben ajustar los marcos conceptuales, las definiciones de política y los instrumentos de intervención a una realidad más compleja (y añadiríamos dinámica) que no se sujete a las orientaciones sectoriales que han constreñido lo rural como sinónimo de agricultura. La coexistencia de comunidades indígenas, las sociedades campesinas, las comunidades asentadas en pequeñas y medianas poblaciones, ponen de relieve una organización social, formas de solidaridad social y prácticas de acción colectiva que se han visto afectadas por una visión de desarrollo y de progreso que las ha excluido (Niño, 2001). La gestión de la sociedad sobre el territorio es por consiguiente, el aspecto neurálgico de la nueva ruralidad. El potencial de la visión multicultural sobre el territorio rural, como se verá más adelante, abre un amplio espectro de posibilidades para una educación intercultural que enriquezca y promueva el desarrollo humano integral de los grupos sociales y las comunidades en que viven.

La vinculación de la nueva ruralidad, en el contexto del proceso de globalización, pone de relieve los profundos cambios que han originado en nuestras sociedades latinoamericanas, independientemente del grado de desarrollo económico y social que hayan alcanzado. Las nuevas condiciones estructurales emergentes implican una reconceptualización de la ruralidad para su interpretación. El concepto de desarrollo rural no se constriñe al exclusivo reconocimiento de los actores sociales que integran la estructura

3 Directora de Desarrollo Rural del Ministerio de Agricultura y Desarrollo Rural de Colombia. social y la sociedad civil rural (campesinos, pequeños y medianos productores...), ni se circunscribe a la esfera específica de las políticas públicas nacionales o al delimitado mundo de lo local. El nuevo foco de atención de lo rural lo constituye el territorio que deviene en el constructo epistemológico central del paradigma de la nueva ruralidad y por consiguiente, en la categoría central que asume una visión holística que vertebra todo el sistema teórico de este paradigma sobre el desarrollo rural.

Así, la nueva ruralidad constituye una reconceptualización de lo rural $^{4}$, desde la centralidad del territorio en el desarrollo rural, tanto en Europa como en América Latina. Ciertamente, la visión del desarrollo rural desde el enfoque territorial replanteó la visión sobre tradiciones del espacio y desarrollo rural. Al respecto, Solís observa:

La aproximación a la ruralidad desde la perspectiva de territorio, de las interrelaciones rural-urbano y de las múltiples opciones que ofrece, tanto en el ámbito agrícola como en el no agrícola, nos proporciona múltiples oportunidades para contribuir al desarrollo, desde lo rural, $y$ al fortalecimiento de la democracia como ha sido señalado por los jefes de Estado y de gobierno de las Cumbres de las Américas (2001: 55).

4 En el contexto del desarrollo teórico de la Sociología Rural tuvo lugar un debate acerca de los alcances de la teoría de la nueva ruralidad. El punto de discusión consistió en si la nueva ruralidad buscaba identificar "nuevos" fenómenos o procesos o si constituía un nuevo enfoque para describir o interpretar lo "viejos" procesos de cambio del mundo rural. Otra dimensión de la controversia fue si se trataba del surgimiento de un nuevo "paradigma", que superaría las viejas categorías o paradigmas anteriores explicativos de las Ciencias Sociales relativos al mundo rural, que habrían perdido su capacidad explicativa-interpretativa (validez epistemológica y hermenéutica), en el contexto de los cambios estructurales que han tenido lugar en el proceso mundial de instauración del capitalismo global (globalización) (Llambí y Correa, 2007: 39). 
En síntesis, la nueva ruralidad, desde el enfoque territorial, se apoya básicamente en las siguientes premisas:

a) Se coloca un marcado énfasis en la dimensión territorial en contraste con la visión sectorial agrícola.

b) Se toma conciencia de las diversas funciones de una actividad agropecuaria que excede lo productivo.

c) Se le debe ver como un proceso que cobra en cada región características específicas, por cuanto interactúan distintas variables económicas, sociales $y$ políticas que confieren a cada territorio una identidad única, con una historia, un presente $y$ una proyección futura construida por la sociedad que interactúa en ese espacio.

d) Se produce una revalorización de la complementariedad existente entre las actividades agropecuarias y el desarrollo de otras actividades económicas rurales no agrícolas que son fuentes de ingreso para la población.

e) Se concede una priorización de la potencial competitividad de los territorios a partir de diversos sectores - por ejemplo, el turismo-y de actividades ligadas a la geografía, la historia, la cultura, la ecología, etc.

Fundamentada en estos supuestos, la ruralidad deviene en un nuevo sentido que orienta la gestión de la sociedad sobre el territorio. Debe comprenderse como territorio limitado y definido a partir de la conformación de asentamientos humanos, de procesos sociales y económicos asociados a la explotación y uso de los recursos humanos. Esta visión, se apoya en una concepción de ruralidad que coloca lo humano y lo social como centro del análisis $y$ de las acciones tendentes al desarrollo rural. Por lo tanto, la conformación social de los espacios rurales se constituye en el centro gravitacional de lo rural. La composición y dinámica de la estructura social del medio rural, el carácter multidimensional de la trama social $y$ vinculación a las diversas actividades económicas, la diversidad de la conformación multicultural, etc., son entre una gran diversidad de aspectos, los que definen la nueva temática de los espacios territoriales del mundo rural.

Albanesi y Preda (2007) definen el territorio como el espacio que comparten todos los habitantes independientemente del uso que se le dé. Con el enfoque territorial, la visión tradicional del desarrollo rural adquiere una dimensión integral y holística, que trasciende la visión exclusivista de la producción agropecuaria y los actores involucrados; con este nuevo enfoque del desarrollo rural, surge la articulación sistémica del espacio rural con el espacio urbano. Pero, a su vez, la concepción territorial se extiende más allá de lo físico-espacial, de las actividades económicas (2007: 254). En el ámbito económico, el enfoque territorial se apoya en una dimensión multisectorial, producto de las actividades económicas generadas por comunidades cada vez más integradas y complejas y más allá de lo productivo, es multidimensional: involucra los aspectos como la cultura, la organización social, el capital humano y la historia. Desde el enfoque territorial, la mayor riqueza de lo rural radica en la construcción de cultura, tradiciones, valores e instituciones, que se expresan en las comunidades indígenas, las sociedades campesinas y comunidades asentadas en pequeñas y medianas poblaciones (Niño, 2001).

Según Pérez y Caballero (2003), la nueva ruralidad le confiere especial importancia a:

a) La dimensión territorial en oposición a la sectorial, así como a las funciones y servicios prestados por la agricultura más allá del aspecto productivo;

b) los vínculos entre las pequeñas ciudades y el campo circundante y la relación entre desarrollo urbano y rural;

c) la complementariedad entre la agricultura $y$ otras ocupaciones;

d) la función residencial de las áreas rurales;

e) la integración de las áreas rurales a los mercados y los procesos de globalización, lo que destaca la importancia de la competitividad territorial frente a la puramente empresarial o sectorial; 
f) el potencial económico que ofrecen los activos ligados al territorio, de tipo geográfico, histórico, cultural, etc. $y$

g) la participación en las políticas y programas de desarrollo rural de los diversos agentes involucrados y la concertación entre ellos (2003: 4).

Un aspecto central de la nueva ruralidad es, ciertamente, la concepción del territorio como un espacio que comparten todos los habitantes independientemente del uso que hacen del mismo. El enfoque territorial de lo rural fue rápidamente asumido — con las presumibles diferencias de enfoque- por los medios intelectuales y además, fue común su utilización en los organismos internacionales de desarrollo, los discursos políticos y en los medios académicos interesados en esta problemática. No obstante, su asunción en las instituciones del Estado y sus políticas tuvieron su dificultad por cierta reticencia de algunos grupos de presión y la tendencia a hacer prevalecer el enfoque sectorial en los aparatos administrativos. Este cambio de enfoque, respecto a lo rural, hace que la visión tradicional del desarrollo rural se desplace de un enfoque constreñido en la producción agropecuaria $y$ los actores involucrados, a la visión integral del desarrollo territorial. En el territorio tiene lugar la interacción social necesaria que posibilita la construcción social en cada proceso específico de desarrollo rural (Albanesi y Preda, 2007).

Asimismo, el territorio constituye el espacio de convivencia humana y de construcción de los marcos de representación simbólicos que le confieren unidad sociocultural y sentido al sujeto y a la colectividad. Es el espacio en que los grupos sociales construyen y participan de la acción social comunicativa para alcanzar sus diversos intereses y objetivos personales, grupales y sociales. Es en este espacio, en el que se configura la identidad personal y colectiva. En el territorio, tiene lugar un marco de interacciones entre los actores sociales que conforman la sociedad civil rural. La cultura rural se construye, por consiguiente, en el territorio como resultado de esa amplia y compleja red de interacciones sociales $y$ de diversos procesos de construcción simbólica y al mismo tiempo, del sujeto, los grupos sociales y la estructura social propia del mundo rural con el medio ambiente $y$ con el territorio urbano, dependiendo del grado de cercanía ya no solo física sino cultural, que poseen los ciudadanos del territorio rural.

\section{LA EMERGENCIA DE LA NUEVA RURALIDAD Y LA PROBLEMÁTICA EDUCATIVA}

El proceso de modernización capitalista, como proceso de cambio estructural, ha influido en el medio rural que pone de relieve importantes cambios, en aspectos tales como: los sistemas productivos, la estructura social, la cultura tradicional, la dinámica de la sociedad civil rural, la diversificación de las actividades agrícolas, la aparición de nuevas estructuras de estilos de vida rural (espacio para el ocio y la recreación, el agroturismo, el turismo verde, el ecoturismo, etc.). Estos ostensibles cambios propios del enfoque territorial, imponen una reconceptualización de la visión del desarrollo rural que justifican el defender y promover aspectos básicos para una educación rural, con rasgos claramente diferentes de la educación que se desarrolla en las zonas urbanas.

Diversas manifestaciones derivadas de los cambios estructurales, ponen en evidencia el proceso de reconfiguración profunda que está experimentando en el medio rural. En efecto, el medio rural experimenta una suerte de transculturación de lo urbano hacia lo rural y de lo global a lo local como tendencia modernizante: una hibridación cultural. La denominada universalidad de la modernización permea el territorio rural arrastrándolo a una extinción de su diversidad y riqueza cultural. Esta hibridación cultural requiere de una respuesta desde la resistencia educativa, una resignificación de la cultura campesina, en la cual el papel de la educación rural es de primer orden.

La defensa de la identidad rural frente a la indiscriminada tendencia de la hegemonía cultural cosmopolita-urbana, imbuida de los antivalores deshumanizados del postmodernismo en su versión hegemónica neoliberal, impone por consiguiente, de una acción estratégica 
tendente al rescate de la cultura rural: los valores, las creencias, los usos, las costumbres, las tradiciones, todo tipo de manifestaciones artísticas, la cultura sociopolítica, la visión del mundo y el autoconcepto del mundo rural. En América Latina, la emergencia de la nueva ruralidad impone nuevas demandas que los Estados no han atendido adecuadamente (o han desconocido). Ya desde principios de la década de 1970, en el Informe Final del Seminario Interamericano sobre problemas de la Educación Rural, se identificaban los principales problemas que enfrenta la educación rural:

$\diamond \quad$ Inequidad: no se cumple el principio democrático de igualdad de oportunidades educativas para la niñez y la juventud rural. Brecha entre la realidad urbana $y$ rural: salud, nutrición, vivienda, organización comunitaria, recreación.

$\diamond \quad$ Déficit del rendimiento escolar: retardo pedagógico, repitencia, ausentismo, deserción o exclusión. No se cumplen los fines educativos y la inversión no resulta eficiente.

$\diamond \quad$ Baja cobertura de la oferta educativa: significativo porcentaje de escuelas solo ofrecen los tres primeros grados de educación básica.

$\diamond \quad$ Centralización: concentración de la política educativa, curricular y administrativa. Ambigüedad en lo referente a una educación rural y agropecuaria.

$\diamond \quad$ Desvinculación entre la educación formal y las modalidades de educación no formal y de adultos: necesidad de repensar la educación rural desde una visión global.

$\diamond \quad$ Escasa pertinencia cultural.

$\diamond$ Desvinculación: entre la escuela y la comunidad.

$\diamond \quad$ Falta de coordinación: entre las diferentes agencias que desarrollan programas educativos para el sector rural.

$\diamond \quad$ Ausencia de variabilidad: en los métodos $y$ procedimientos de enseñanza.

$\diamond \quad$ Dotación deficitaria: de material didáctico. $\diamond \quad$ Falta de eficiencia: en la supervisión escolar.

$\diamond \quad$ La evaluación escolar: es infuncional.

$\diamond \quad$ Baja compenetración docente con la comunidad: bajos salarios y condiciones de vida.

$\diamond \quad$ Insuficiencia de programas de asis-tencia escolar: baja capacidad de las organizaciones comunitarias para gestionar ayuda de servicios asistenciales.

\section{$\diamond \quad$ Inadecuada edificación escolar.}

Datos más recientes ponen de relieve la dramática situación de la educación rural, en particular, de la educación básica en la región latinoamericana y caribeña. En acceso a la escuela, el $15 \%$ de niños y niñas de sectores pobres no tiene acceso a esta. Después de los 6 años, la edad de ingreso a la escuela está entre 10\% y 15\% de los niños $y$ niñas. En cuanto a los años de escolaridad, solo el $47 \%$ de los niños y niñas que ingresan a primer grado, concluyen la educación primaria; el promedio es de 4 años de escolaridad (Méndez, 2003).

Esta realidad lejos de haber sido superada, ha seguido profundizándose a lo largo de las décadas siguientes hasta el día de hoy. Los esfuerzos de los organismos internacionales y regionales por intervenir en la solución de la brecha educativa urbana-rural, pone de relieve el grado de complejidad y profundidad de una problemática tendente al crecimiento. Organismos internacionales, tales como la Organización de las Naciones Unidas para la Agricultura y la Alimentación (FAO) y la Organización de las Naciones Unidas para la Educación, la Ciencia y la Cultura (UNESCO), coinciden en que la educación es uno de los derechos fundamentales del ser humano y un requisito básico para reducir la pobreza, para mejorar las condiciones de vida del mundo rural y para construir seguridad alimentaria. Al mismo tiempo, concuerdan en que en las áreas rurales el nivel de educación es todavía más bajo que en las áreas urbanas, el analfabetismo es mayor y la calidad de la educación es más baja. 
Para aumentar los esfuerzos tendentes a abordar las disparidades rurales teniendo como objetivo central las necesidades de la educación de la población rural, se plantearon los siguientes objetivos:

$\diamond \quad$ Superar las diferencias entre la educación rural y urbana.

$\diamond \quad$ Incrementar el acceso a la educación primaria de la población rural.

$\diamond \quad$ Promover $y$ fortalecer la capacidad nacional para planificar e implementar los planes de educación primaria abordando las necesidades de aprendizaje de la población rural. Concientizar sobre la importancia de la educación para la población rural, como un paso crucial para alcanzar los objetivos del Milenio; en particular, erradicar la pobreza extrema y el hambre, lograr la enseñanza primaria universal y promover la igualdad entre los géneros.

\section{LOS RETOS DE LA EDUCACIÓN PARA LA NUEVA RURALIDAD Y LOS FUNDAMENTOS CURRICULARES PARA LA FORMACIÓN DOCENTE}

En este apartado se plantea, sin ánimo de exhaustividad, algunas dimensiones fundamentales de la nueva ruralidad desde la visión territorial que se han constituido en necesidades educativas. Desde el punto de vista metodológico, se formulan algunos aspectos educativos neurálgicos que emergen de la relación nueva ruralidad-educación que, a nuestro juicio, se imponen como retos para la formación de los docentes rurales. Se considera que existe la imperiosa necesidad de traducir estas demandas educativas en respuestas curriculares en el ámbito de la formación docente, en aras de establecer un perfil académico-profesional para los y las docentes que trabajan y trabajarán en el medio rural. Para efectos expositivos, se realiza una breve exposición de los que se consideran los principales retos educativos emergentes, que han surgido como parte del proceso de configuración de la nueva ruralidad (los cuales se constituyen en fuentes curriculares) proponiendo para cada uno los núcleos temá- ticos indispensables. Estos núcleos temáticos se constituyen, según esta tesis, en los fundamentos curriculares (núcleos de conocimiento teóricos y prácticos, disciplinarios e interdisciplinarios) de los planes de formación de los y las docentes rurales ${ }^{5}$.

Un ejercicio como el que se propone, exige la tarea de delimitar la interrelación entre la nueva ruralidad — desde el enfoque territorial-y los cambios educativos que se deberían de asumir para emprender el camino de un desarrollo rural que integre, en la vida social de las poblaciones, la sostenibilidad ambiental y una visión del desarrollo humano integral. La contribución del sistema escolar en el medio rural al desarrollo visto en forma integral, implica una visión del cambio educativo que se pretende promover. $\mathrm{Al}$ respecto, parece muy pertinente la acotación sobre el cambio educativo que realizan González y Escudero:

Cuando hablamos de cambio educativo estamos refiriéndonos a un complejo espectro de fenómenos, utilizando una considerable pluralidad de conceptos $y$ perspectivas teóricas e ideológicas desde las que tratamos de analizar, explicar, comprender $y$ orientar posibles prácticas y decisiones tendentes a la mejora de la escuela (1987: 11).

La delimitación del cambio educativo en el contexto rural es una tarea que exige un posicionamiento epistemológico, desde el cual se asume una visión orientada a comprender la interacción dialéctica entre los cambios estructurales -que tienen lugar en el universo rural-y la compleja dinámica de cambios ideológicos que se manifiestan en cualquier dimensión discursiva respecto de esos cambios (ej.: debates teóricos, debates políticos, artículos académicos y de organismos internacionales, propuestas de políticas públicas, artículos periodísticos, propuestas programáticas de toda índole, etc.). Los debates ideológicos, especialmente

$5 \quad$ En adelante, en los subtítulos de este apartado los Fundamentos Curriculares para la Formación Docente Rural aparecerán bajo las siguientes siglas: FCFD. 
políticos, influyen directamente en el debate educativo sobre las opciones de cambio societal. Una comprensión auténticamente objetiva de este complejo proceso, exige incursionar entre las interdeterminaciones estructurales que configuran esos debates. Por lo tanto, la definición de González y Escudero requiere de una delimitación epistemológica en el sentido de que el cambio educativo, como objeto de estudio, implica asumir una perspectiva hermenéutica. Esto es, el análisis, la explicación, la comprensión y la orientación de las prácticas y decisiones para mejorar la educación que deben realizarse, desde una aproximación crítica, a partir de la interacción dialéctica entre los procesos histórico-estructurales de cambio que se escenifican en la sociedad global y los cambios educativos que se derivan de esa interacción. Esta consideración, por consiguiente, es válida y necesaria para construir una visión del cambio educativo, contextualizado en los cambios estructurales que han traído aparejados al fenómeno de la nueva ruralidad.

\subsection{DESARROLLO DE UNA CULTURA PEDAGÓGICA RURAL}

Las escuelas rurales deben desarrollar procesos pedagógicos de calidad íntimamente vinculados a las prácticas sociales de la comunidad rural. En el contexto rural, el vínculo esencial del proceso educativo, desde el enfoque territorial, debe tener como centro gravitacional la sociedad civil rural. Debe existir una clara identificación de los principales actores sociales, económicos, políticos y culturales que integran la sociedad civil y dar una respuesta educativa que posibilite formar ciudadanos conscientes y participativos en la atención de las demandas sociales más relevantes de las comunidades rurales. En particular los centros educativos, desde las escuelas unidocentes hasta las sedes regionales de las universidades, públicas y privadas, deben promover una cultura educativa de fuerte raigambre rural, atendiendo las particularidades del espacio territorial: sus particularidades sociales y culturales, sus necesidades de fortalecimiento de la equidad social y de compromiso contestatario en la defensa del medio ambiente, entre muchas más con las que es necesario identificarse y comprometerse desde la práctica educativa. Un conjunto de acciones como las que se propone requiere de establecer una cultura pedagógica rural, que anime todas las prácticas educativas y la acción permanente de conferirle pertinencia sociocultural al desarrollo curricular en los territorios rurales.

\section{FCFD: CULTURA PEDAGÓGICA RURAL Y RECONCEPTUALIZACIÓN DE LA PRÁCTICA EDUCATIVA RURAL}

Desde la práctica docente, una tarea perentoria es la revalorización del mundo rural; ello implica asumir el derecho a la defensa y promoción permanente de una educación rural con rasgos claramente diferentes de la educación que se desarrolla en las zonas urbanas, de manera diferenciada $y$ al mismo tiempo complementaria. Esta acción implica asumir, asimismo, una decidida defensa de la identidad rural como parte de la cultura pedagógica rural. La cual debe ser crítica y contestataria en defensa de la cultura rural. Como se ha observado en los apartados precedentes, la nueva ruralidad es la manifestación de los cambios estructurales que están teniendo lugar en el mundo rural. Cambios profundos y acelerados que inciden sistemáticamente en la construcción y cambio de los marcos de representación simbólica de la población rural, su visión del mundo y sus prácticas y patrones socioculturales. Esto requiere, por consiguiente, de reconceptualizar la práctica pedagógica en el medio rural a la luz de la sistematización y desarrollo de una cultura rural que retome sus propios valores, usos, costumbres $y$ tradiciones.

Según se menciona de manera sintética anteriormente, la característica más significativa de los cambios estructurales del medio rural, es que están sometidos a una reconfiguración profunda. Una respuesta a estos procesos y tendencias requiere inequívocamente de promover un cambio radical en la formación de los/as educadores/as rurales. Al respecto, deben incluirse en los planes de estudio, a nivel de grado y posgrado, contenidos y prácticas curriculares que le posibilite a los docentes en servicio (como formación continua) y a los 
$y$ las futuros docentes rurales, instrumentos, además, de los medios para identificar y analizar críticamente esos cambios. Contenidos metodológicos, tales como, el análisis de coyuntura, el diagnóstico rural, etc. deberían incluirse como contenidos teórico-metodológicos en los planes de formación.

Solo mediante la adquisición de estas competencias metodológicas-analíticas será posible establecer de manera creativa y crítica mediaciones pedagógicas basadas en una visión socioconstructivista, que le permita interpretar esos cambios estructurales y socioculturales en el medio rural e incorporarlos en el proceso de desarrollo curricular en el aula.

La orientación de este proceso obedece, por lo tanto, a los siguientes propósitos.

$\diamond \quad$ Enriquecer la práctica educativa rural con sus estudiantes (desarrollo curricular).

$\diamond \quad$ Que el educador rural se constituya en un actor crítico y propositivo para participar en su condición de educadorciudadano, en la promoción del mejoramiento de las condiciones de vida de las comunidades rurales.

$\diamond \quad$ Desde el punto de vista curricular, los y las docentes debe ser capaces de enriquecer el desarrollo del currículo, apoyándose en las fuentes curriculares del medio sociocultural $y$ natural en que desenvuelven las comunidades rurales.

\subsection{PRÁCTICA PEDAGÓGICA RURAL Y RESIGNIFICACIÓN DE LA CULTURA CAMPESINA}

Las políticas curriculares deben propiciar una práctica pedagógica auténticamente rural, vinculada al medio sociocultural y estructural en que se desenvuelven los niños y jóvenes. Los contenidos deben estar cargados de sentido de valoración de lo rural y ser pertinentes culturalmente para los y las estudiantes. Aquí se quiere retomar lo relativo a la resignificación de la cultura campesina, tan trastocada por la imposición hegemónica de una cultura burguesa posmodernista que la mediatiza, la instrumentaliza y la mercantiliza. Ciertamente, la cultura posmodernista del mercado consumista y la visión mercantilizada de la industria turística en las zonas rurales contribuye a la implantación ideológica de una cultura campesina "folklorista", despojada de la riqueza cultural propia y humana de la cultura campesina. Este ejemplo, se extiende a la cultura paisajística, la cultura productiva propia del mundo rural y sus prácticas agroecológicas de respeto y de preservación de la naturaleza. En el ámbito de la racionalidad económica neoliberal del capitalismo global, todo es objeto de mercantilización para ponerlo a la disposición, como producto, del mercado.

La hegemonía cultural posmodernista es la causa de la hibridación cultural, esto es, de la preeminencia de lo urbano frente a lo rural y de lo global sobre lo local (Mendoza, 2004). El rescate de la cultura rural, de sus valores, sus creencias, sus usos, sus costumbres, sus tradiciones, todo tipo de manifestaciones artísticas, la cultura sociopolítica, la visión del mundo rural, representa por lo tanto, el elemento axial de una propuesta contestataria. En esta perspectiva, las prácticas pedagógicas rurales como resistencia a la universalidad de la cultura capitalista global, debe constituirse en fundamentos del currículo y ejes de la práctica pedagógica. Los campesinos y campesinas son los sujetos sociales que le confieren razón de ser a la vida rural, en consecuencia, la resignificación de la cultura campesina deviene en un pilar básico para preservar la cultura rural y campesina.

El rescate y la defensa de la cultura rural y campesina no implican de ninguna manera el cerrar las puertas a la cultura posmodernista universal propia del denominado proceso de planetarización. Antes bien, la premisa básica debe ser: desde lo local a lo planetario y desde lo planetario a lo local. Por lo tanto, la visión desde lo local debe servir de base para acercarse a lo planetario en aras de enriquecer lo local, asumiendo desde una interpretación crítica, las dimensiones culturales humanistas $y$ otras expresiones constructivas de diversa índole que entraña el proceso de planetarización. La planetarización, como observa Baquedano (1999), implica una reacción a la globalización que enlaza la base social y que persigue un vínculo que abarca lo nacional y lo internacional. Señala también que la lógica de la planetarización es la de construir 
una civilización planetaria basada en todas sus partes, sin sacrificar o excluir alguna de ellas. Esta posición es la misma asumida por los acuerdos de la Cumbre de la Tierra, Río 92 y apoyada por la ONU, los gobiernos que la integran $y$ otros organismos y actores internacionales.

\section{$\diamond \quad F C F D: G L O B A L I Z A C I O ́ N$, INTERDISCIPLINARIEDAD Y PERTINENCIA CULTURAL DE LA PRÁCTICA PEDAGÓGICA RURAL}

De lo expuesto es posible colegir que la promoción sociocultural y educativa de la cultura rural conlleva un decidido compromiso de acción con el rescate y la revaloración de la cultura rural, sin despreciar los valores humanísticos universales de la cultura planetaria. Estas acciones se deben complementar, al mismo tiempo, con una resistencia contra los valores deshumanizantes que propaga el capitalismo global y su racionalización económica-cultural neoliberal. El conocimiento multidisciplinario e interdisciplinario de los desarrollos teóricos y metodológicos sobre la cultura como realidad compleja es fundamental. En este sentido, en la estructura curricular de los planes de estudio de los futuros educadores rurales y en los programas de formación continua se deben considerar los aportes de la antropología social, de la sociología de la cultura, de la psicología cultural y de otras disciplinas en su contribución a la comprensión de los fenómenos de la cultura rural.

Los planes de estudio de los/las docentes rurales deben privilegiar los enfoques curriculares que enfatizan la pertinencia sociocultural, en aras de superar la barrera cultural urbanorural que predominan en los planes de estudio oficiales planificados curricularmente para la población estudiantil urbana. Desde el punto de vista de la teoría curricular, las contribuciones de la pedagogía crítica y la sociología crítica en contra de las posiciones reproductoras del conocimiento y de la cultura oficial, deben incluirse en los planes de formación de los educadores rurales. El logro de este objetivo contribuirá a la superación de la barrera cultural urbano-rural y la realización de un proceso de desarrollo curricular que devele la aparente neutralidad ideológica de la política curricular (conocimiento oficial). Se trata de combatir la aparente neutralidad ideológica de los currículos oficiales que no propician el desarrollo humano integral y la participación ciudadana crítica de la población rural.

En el contexto de la planetarización, la realización de una práctica educativa auténticamente rural requiere del desarrollo de las competencias, para que los y las docentes rurales puedan concretar y desarrollar la pertinencia cultural del currículo en sus prácticas pedagógicas. Como bien lo apunta Peralta (1996), la pertinencia cultural comprende considerar los aspectos formales, estructurales $y$ de fondo o contenido, $y$ advierte acertadamente que una aproximación superficial a ella podría significar convertirla solo en "materias" (a propósito del currículo académico). Por consiguiente, plantea la necesidad de "permeabilizar y flexibilizar el currículo" en sus aspectos estructurales tomando en consideración los aportes de ciertas culturas distintas a la occidental, desde una perspectiva holística, esto es, que considere integralmente la totalidad de la sociedad global.

En los planes de formación de los y las docentes rurales deben de incluirse contenidos teóricos, metodológicos e instrumentales, tales como investigación-acción, observación participante y como se ha mencionado, métodos $y$ técnicas etnográficas $y$ otros que posibiliten realizar, en su desempeño profesional y su vida ciudadana, estos acercamientos críticos indispensables al conocimiento de los cambios que tienen lugar en los territorios rurales.

\subsection{CURRÍCULO Y PRÁCTICAS PEDAGÓGICAS RURALES}

La cultura escolar rural debe ser congruente con la realidad del medio rural, respetando la idiosincrasia sociocultural de la población rural. Los contenidos, como objetos de conocimiento, deben ser significativos a la población estudiantil rural para que sean asimilados $y$ no les resulten extraños. En el medio rural, la descontextualización del currículo es una de las más marcadas tendencias en América Latina. Se considera con Magendzo (1986: 139) que es preciso para impulsar cambios significativos en 
la educación, repensar la cultura y por ende, repensar el currículo. La orientación fundamental es concebir, como lo plantea este autor, el desarrollo integral del sujeto social, de sus fuerzas creadoras, necesidades, capacidades y formas de comunicación. En consecuencia, la formación docente rural debe comprender el dominio de competencias pedagógicas, desde una visión sociocontructivista $y$ de aprendizaje con significado, que permita la contextualización del currículo y por consiguiente, el desarrollo humano integral del sujeto $y$ de la colectividad como un todo.

En el contexto de la educación rural, esto adquiere especial relevancia para incorporar adecuaciones curriculares a los cambios que impone la nueva visión territorial de la nueva ruralidad. En efecto, propuestas como el Currículo Comprehensivo de Abraham Magendzo (1986) o el Currículo Orientado al Desarrollo Humano Integral (CODHI) de Ángel Villarini (1997) que se retomará más adelante son, a guisa de ejemplo, propuestas latinoamericanas de desarrollo curricular que enriquecerían las prácticas de una educación rural. Estos enfoques curriculares alternativos establecen vinculaciones concretas de una relación: currículo-cultura-estrategias pedagógicas. Así, la visión familiar, comunitaria y social se visualizaría con la dimensión crítica y emancipadora, frente al carácter reproductor y dominador del currículo académico-disciplinario que prevalece, como enfoque curricular en América Latina. El posicionamiento epistemológico en los enfoques curriculares críticos, tales como los derivados de la visión socioconstructivista, teoría crítica, pedagogía crítica, sociología crítica, etc. y la adquisición de las competencias de diseño y desarrollo del currículo, en todas sus dimensiones, constituyen aprendizajes $y$ competencias indispensables para que los y las docentes rurales puedan desarrollar una práctica educativa basada en los cambios estructurales que tienen lugar en los territorios rurales.

\section{$\diamond \quad$ FCFD: PEDAGOGÍA CRÍTICA, HERMENÉUTICA CRÍTICA Y PLANIFICACIÓN CURRICULAR}

Desde la visión crítica expuesta, el currículo formativo de los y las docentes rurales debe incorporar en la estructura curricular del plan de estudios, áreas del saber provenientes de la nueva visión que aporta la pedagogía crítica y la sociología de la educación crítica en lo relativo al desarrollo curricular. De igual manera, los aportes de disciplinarias, tales como la pedagogía crítica, hermenéutica crítica, sociología de la educación crítica, semiótica y otras similares, deben de apoyarse en visiones como la teoría crítica, el análisis ideológico, el análisis crítico del discurso, etc., para que dispongan de un acervo teórico-metodológico que les permita desarrollar las competencias para analizar críticamente el contexto rural y poder enriquecer su práctica pedagógica.

Ciertamente, en la perspectiva de la pertinencia cultural del currículo, es preciso, que los y las docentes rurales adquieran las competencias teóricas y prácticas, para poder interpretar críticamente la cultura rural y realizar las adecuaciones curriculares que permitan aprendizajes significativos con los estudiantes de todos los niveles y modalidades del subsistema educativo rural. Alcanzar una meta tan esencial como la de desarrollar un currículo pertinente culturalmente, implica como lo ha indicado Magendzo (1986), que los procesos de planificación curricular, la oposición al currículo unitario y a su aparente superación, con una simple enunciación del concepto de flexibilidad curricular en la fundamentación de los planes de estudio. Su propuesta sostiene que en la adaptación a las necesidades locales y escolares se requiere necesariamente de crear las condiciones que la hagan posible y de una planificación curricular descentralizada. Este tipo de planificación curricular en el espacio territorial rural, ciertamente, abriría un mundo de posibilidades para la realización de una práctica de desarrollo curricular que favorezca una práctica pedagógica auténticamente rural.

\subsection{PRÁCTICA PEDAGÓGICA PARA LA CONSTRUCCIÓN DE UNA CULTURA ESCOLAR RURAL}

La cultura escolar rural se debe construir, a nuestro juicio, a partir de una consciente adscripción de los fundamentos del paradigma epistemológico del socioconstructivismo. Este paradigma es, por sus fundamentos epistemológicos 
$y$ su incidencia individual y social, un excelente instrumento para la construcción de una cultura pedagógica genuinamente rural. Como lo expresa Jonnaert, el socioconstructivismo es "una hipótesis epistemológica según la cual un sujeto construye conocimientos a partir de lo que ya conoce" (2002: 10) y que asimismo, parte del reconocimiento de la necesidad de que el alumno participe activamente en la construcción de conocimientos. El adoptar este paradigma pedagógico implica para los y las docentes, un indispensable cuestionamiento, como observa este autor. Esta visión adquiere una particular importancia para el desarrollo de una práctica educativa auténticamente rural que promueva en el marco de la nueva ruralidad, el rescate y valoración cultural de las mejores tradiciones de los territorios rurales.

Ángel Pérez Gómez ha definido el concepto de cultura en los siguientes términos:

Considero una cultura como el conjunto de significados, expectativas y comportamientos compartidos por un determinado grupo social, que facilitan y ordenan, limitan y potencian, los intercambios sociales, las producciones simbólicas y materiales $y$ las realizaciones individuales y colectivas dentro de un marco espacial y temporal determinado (1999: 16).

Como bien lo ha observado este autor, la comprensión de los fenómenos de socialización y educación que ocurren en la escuela, debe basarse en la resignificación de la cultura, concebida como configuración sistémica, de carácter indeterminado y ambiguo, abierto a la interpretación, naturaleza implícita de los contenidos, relevancia vital de sus determinaciones. En esa misma dirección, señala que no se trata de un simple cambio de denominaciones, sino de perspectivas que posibiliten interpretar lo que ocurre en la vida cotidiana de la escuela, en el efecto sobre los pensamientos, sentimientos y conductas de los estudiantes, este cambio - puntualiza - requiere descender a los intercambios subterráneos. Su tesis consiste que las diferentes culturas se entrecruzan en el espacio escolar, condicionando el desarrollo de la construcción de significados de cada sujeto, el sentido de los intercambios y el valor de las transacciones simbólicas (Pérez Gómez, 1999: 16).

Si se asume que la cultura escolar rural se construye mediante la construcción de significados para toda la comunidad educativa, esa construcción impone, por consiguiente, una recontextualización y reconceptualización de la práctica educativa en el marco de los cambios estructurales $y$ socioculturales que se derivan de la nueva ruralidad y que tienen lugar en un determinado territorio. Desde esa misma visión, este proceso debe considerar, como lo observa Mendoza (2004), el llamado "giro lingüístico", esto es la superación del lenguaje como un simple instrumento de transmisión de contenidos conceptuales cerrados, para adoptar un enfoque constructivo del mismo. Es preciso admitir, por lo tanto, que los contenidos significativos se elaboran en procesos comunicativos, históricamente contextualizados que implican actos de resignificación. Este proceso entraña una particular importancia, en el contexto rural, porque es precisamente en la esfera de la cultura escolar en donde se realizan la relación pedagógica, esto es, donde ocurre el proceso de enseñanza-aprendizaje.

\section{$\diamond \quad F C F D:$ CONSTRUCCIÓN DE SIGNIFICADOS, APRENDIZAJE SIGNIFICATIVO $Y$ SOCIOCONSTRUCCIONISMO}

Con base en el planteamiento anterior, parece de particular importancia subrayar que en los procesos de elaboración de los conocimientos, los educadores $y$ las educadoras deben asumir un posicionamiento epistemológico crítico en su práctica pedagógica. La realidad es que si no hay una adscripción epistemológica conciente y crítica de la práctica pedagógica, los y las educadores asumirán el conocimiento oficial con una aparente neutralidad ideológica. En este hecho subyace una verdad que no se hace manifiesta: el conocimiento oficial les es impuesto irremediablemente, sin que haya conciencia del significado de las muy diversas maneras en que la hegemonía política y cultural se impone, desde el nivel más alto de la toma de decisiones en la esfera de la política educativa. Los medios e instrumentos serán las orientaciones estatales educacionales, los 
enfoques curriculares explícitos o implícitos, las mediaciones pedagógicas, las diversas formulaciones curriculares (planes y programas de estudio, métodos didácticos y de evaluación, etc.) que al final se manifestarán en la relación educativa del aula. Esa inconsciencia ideológica, en el ámbito educativo, da lugar a una práctica pedagógica de apariencia neutral que asume acríticamente el contenido hegemónico del conocimiento oficial. En el caso de los países en que la política educativa no considera una distinción específica de orientaciones curriculares para el medio rural, pertinentes socioculturalmente, se acentúan los obstáculos para el desarrollo de una práctica pedagógica rural, acorde con las genuinas necesidades educativas de su población escolar.

Ángel Pérez (1999) afirma que la cultura:

... es el resultado de la construcción social contingente a las condiciones materiales, sociales y espirituales que dominan un espacio y un tiempo; [y se] expresa en significados, valores, sentimientos, costumbres, rituales, instituciones y objetos, sentimientos (materiales $y$ simbólicos) que rodean la vida individual y colectiva de la comunidad.

A esta concepción de la cultura, habría que completarle que todo ese complejo proceso tiene lugar sobre la base de la producción material, desde el punto de vista económico y en el marco de un complejo sistema de relaciones sociales. Esto constituye la base material de producción cultural que a su vez, es parte de la misma cultura. Una visión como esta de la cultura requiere de una permanente "lectura" de sus mutaciones $y$ transformaciones para colocar los aspectos que serían objeto de aprendizaje en un contexto educativo y por tanto, de desarrollo curricular y de relaciones pedagógicas. Los cambios en el mundo rural ponen de relieve esta realidad. Ciertamente, los espacios territoriales rurales dan cuenta de una realidad que cada vez más se aleja de la visión tradicional de la cultura rural en las décadas pasadas. He aquí un enorme reto educativo para las comunidades rurales y su población estudiantil $y$ en consecuencia, para la formación docente.
A tenor de lo expuesto, se concluye que la formación de los docentes rurales debe contemplar un equilibrio en la estructura curricular entre la dimensión teórica y la práctica en situaciones concretas. Siendo que la formación de los y las docentes rurales debe realizarse en el mismo medio rural, este debe ser el referente contextual analítico crítico en que tiene lugar la formación docente. Por lo tanto, un aspecto fundamental debe ser el ejercicio de la interpretación y construcción de significados tendente a producir actos de resignificación del universo rural. La construcción comunitaria de los elementos de una cultura escolar: normas, mitos, símbolos, ritos, lenguaje y comunicación, producciones, valores, supuestos básicos (Martínez Otero, s.f.), debe ser una las principales acciones de configuración de una cultura escolar rural y asimismo, una fuente de aprendizaje y formación para la población estudiantil de las comunidades rurales. Este proceso participativo debe ser promovido por los y las docentes rurales. En esta dirección, es preciso formar educadores rurales que tengan las competencias teóricas y sobre todo la motivación de participar creativamente en este proceso.

Como corolario de las consideraciones expuestas, se concluye que en la formación del educador rural, por consiguiente, es necesario introducir desde una visión y una práctica pedagógica integrada, el aprendizaje significativo y una visión socioconstructivista. Esa misma formación debe ser autoreflexiva, para que su aprendizaje implique en su práctica educativa rural una asunción consciente y crítica de la necesidad de desarrollar en las aulas un aprendizaje significativo $y$ constructivista con sus estudiantes, que tome en consideración la diversidad sociocultural. Esta práctica debe desplegarse de manera particular en aquellos territorios rurales en los cuales prevalece la coexistencia de la diversidad étnica, multicultural y lingüística.

Asimismo, en aras de una práctica pedagógica tendente a la construcción de una cultura escolar rural, se estima importante que en la formación docente de los educadores rurales se incluya un alto componente de contenidos en los campos de la investigación-acción y en 
los métodos y en las técnicas etnográficas. La intención es que los docentes rurales adquieran las competencias formativas para asumir un posicionamiento epistemológico y desde su visión puedan analizar, comprender, investigar $y$ enriquecer el desarrollo curricular $y$ en general, su práctica pedagógica para interpretar los procesos de construcción de significados en la cultura escolar rural, los procesos educativos en el medio rural y contribuir crítica y propositivamente en el desarrollo rural integral de su territorio.

\subsection{NUEVOS MODELOS DE RAZONAMIENTO Y DE INTERPRETACIÓN FRENTE A LOS CAMBIOS EN EL MUNDO RURAL}

El desarrollo cognitivo hacia nuevos modelos de razonamiento, tanto de los alumnos como de los docentes, debe ser una respuesta a los cambios que ha traído aparejados la nueva ruralidad en América Latina. Esto supone la superación de una simple percepción acrítica y ahistórica de la realidad del mundo rural que se plantea, a nuestro entender, como un imperativo para arribar a una percepción integral y concreta de los procesos de construcción simbólica y de los marcos de representación simbólica, que representan los cambios de la nueva ruralidad. Realizar con todas sus implicaciones una práctica educativa $y$ pedagógica auténticamente rural supondría superar el mundo de la apariencia, a partir del cual los educadores perciben la realidad en todas sus dimensiones.

Asumir una visión crítica requiere, en consecuencia, de un posicionamiento epistemológico y de un dominio de los conocimientos, competencias, metodologías y de un instrumental técnico que posibilite develar la barrera de lo aparente, para trascender al conocimiento de lo concreto. Esta visión dialéctica de la realidad posibilitará superar la visión positivista y las relaciones funcionales ahistóricas del medio rural en que tiene lugar la práctica educativa rural. Desde la óptica dialéctica, se trata de asumir un enfoque investigativo de la educación en su contexto social superando la reificación, esto es la visión en que subyace la idea nuclear de que el mundo socialmente construido parezca natural e inevitable, negando la historia y el papel de las construcciones humanas en los fenómenos sociales. Al respecto Popkewitz (1997) expresa que la reificación representa un argumento conservador que hace que lo social aparezca como natural e inevitable, eterno, sin diversas interpretaciones, conflictos socioculturales o intereses sociales.

Se ha analizado en otro artículo (Miranda, 2006) ${ }^{6}$ la necesidad de un acercamiento hermenéutico crítico, a partir del cual se ha explicado que las representaciones del objeto de conocimiento se hacen pasar como la cosa misma, con lo cual se crea una apariencia ideológica. Al respecto, se apunta que al contrario de las visiones positivistas (en cualesquiera de sus expresiones paradigmáticas; funcionalismo, estructuralismo, etc.):

... la (visión) dialéctica busca superar la espontaneidad de la percepción del pensamiento cotidiano como realidad, del pensamiento común como forma ideológica del obrar humano de cada día, de las representaciones asumidas por el sujeto como realidades, como atributos naturales de la cosa y de la realidad, sustraídas de las condiciones históricas petrificadas en la conciencia del sujeto (Miranda, 2006: 104).

6 Estos aspectos que se han analizado en el artículo: Hacia una visión hermenéutica crítica de la politica educativa (Miranda, 2006) se ven complementados con la tesis de que ámbitos heurísticos como el de la percepción e investigación de la realidad socioeducativa y de la misma práctica pedagógica, se formulan con argumentos de pretensión de validez universal en sus atributos $y$ cualidades. Estos argumentos constituyen falacias de demostración al concebir las diferencias en percepciones homogéneas y al sustraer las prácticas humanas, sociales y escolares de sus determinaciones históricas, haciéndolas independientes del tiempo y del espacio (resultantes de la reificación). Como se ha observado, este acercamiento epistemológico y hermenéutico positivista y empirista "(...) desnaturaliza el conocimiento, reduciendo la complejidad de las prácticas sociales y de la escolarización a un plano unidimensional de un presente, sin pasado". 
• FCFD: NUEVOS MODELOS DE RACIONAMIENTO, ANÁLISIS ESTRUCTURAL-COYUNTURAL

La formación del docente rural debe tender hacia el desarrollo de las capacidades para asumir nuevos modelos de razonamiento que produzcan nuevos epistemes. Esto requiere de una formación basada en el desarrollo cognitivo de los docentes, que les posibilite asumir nuevas organizaciones de conocimiento bajo presupuestos de un nuevo paradigma cognitivo, acorde con los vertiginosos cambios producidos por la nueva ruralidad. La adquisición de las competencias para la generación de nuevos epistemes y de una práctica pedagógica auténticamente rural, requiere del manejo teórico y metodológico del análisis estructural y de la metodología del análisis de coyuntura, como componentes fundamentales que debe incorporarse en los planes de formación de las y los educadores rurales. La adquisición de las competencias en estos ámbitos posibilitará la realización de diagnósticos rigurosos que enmarquen una estrategia de acción que enriquezca la práctica educativa rural y al mismo tiempo, promueva un estilo de vida democrático cuyo centro gravitacional sea la participación crítica y constructiva de los ciudadanos y principales actores educativos del territorio rural.

Otra dimensión significativa desde el punto de vista de los nuevos razonamientos, es la que señala Lacki (2000), cuando observa que en América Latina es necesaria una desmitificación de la "imprescindibilidad" de las soluciones paternalismo-dependientes, para ser reemplazadas por soluciones educativo-emancipadoras que permitirían conciliar escasez de recursos con eficiencia empresarial. Como lo apunta, la eficiencia dejó de ser una ventaja competitiva para los agricultores, para convertirse en una capacidad de sobrevivencia en la actividad agrícola. Es esta una dimensión que desde la escuela rural se debe asumir al desarrollar una cultura emprendedora, un espíritu innovador y una visión empresarial desde la llamada formación inicial o la educación primaria.
๖ FCFD: EPISTEMOLOGÍA DE LA EDUCACIÓN, HERMENÉUTICA CRÍTICA

¿Qué es lo que se propone como parte fundamental de la formación de los y las docentes rurales, con la asunción de un acercamiento hermenéutico crítico a la comprensión de los fenómenos educativos $y$ en particular, en el contexto de la nueva ruralidad?

En oposición a las visiones reduccionistas (asociacionista, funcionalista, conductista, estructuralista, etc.) en la percepción y conocimiento del fenómeno educativo (en cualesquiera de sus expresiones o determinaciones) es que se ha planteado un acercamiento hermenéutico crítico del conocimiento (Miranda, 2006); acercamiento que se considera pertinente $y$ necesario en la visión de la realidad educativa de los y las docentes rurales. La tesis nuclear en que se ha basado esta aproximación crítica al respecto, radica en el principio dialéctico (y cognitivo) de que la comprensión del fenómeno educativo (como objeto de conocimiento), desde su ámbito macrosocial (sistema social en su conjunto) hasta su ámbito microeducativo (práctica pedagógica en el aula), concreta la superación de las apariencias de las representaciones de los fenómenos educativos. Es bajo este argumento teórico y práctico, que se apunta en Miranda (2006) que, al contrario de las visiones positivistas (en cualesquiera de sus expresiones paradigmáticas: funcionalismo, estructuralismo, etc.), la (visión) dialéctica busca superar la espontaneidad de la percepción del pensamiento cotidiano como realidad, del pensamiento común como forma ideológica del obrar humano de cada día, de las representaciones asumidas por el sujeto como realidades, como atributos naturales de la cosa $y$ de la realidad, sustraídas de las condiciones históricas petrificadas en la conciencia del sujeto.

Expresado de manera sintética la hermenéutica crítica, según la visión que se ha propuesto en el citado artículo, persigue desde un posicionamiento de la teoría crítica, comprender que los cambios sociales se producen en estructuras dinámicas que están sometidas a transformaciones continuas, que se despliegan en los contextos propios de la vida social en que se escenifica la praxis humana. El sustento de esta posición consiste en que las estructuras 
sociales no son estables, por estar sometidas a continuidades $y$ discontinuidades en todas sus dimensiones y por consiguiente, experimentan equilibrios inestables producidos por los procesos histórico-estructurales que los producen, creando la inestabilidad que culmina en el inicio de un nuevo proceso. Así, una hermenéutica crítica de los cambios en el medio rural y particularmente, en el ámbito educativo rural, pretendería interpretar las prácticas que tienen lugar en sus procesos educativos concretos, (i) tomando como núcleo explicativo fundamental sus interacciones dialécticas con los cambios estructurales (dimensión estructural), (ii) analizando la génesis de su evolución como prácticas sociales (dimensión histórico-genética) y (iii) analizando críticamente los procesos de acción comunicativa que generan (procesos de construcción simbólica y de significados).

\subsection{EL CURRÍCULO Y LAS METAS SOCIOCULTURALES NECESARIAS PARA PROMOVER EL DESARROLLO INTEGRAL DE LAS ZONAS RURALES}

En aras de alcanzar las metas socioculturales necesarias para promover el desarrollo integral de las zonas rurales, es un imperativo establecer lo que se ha denominado sostenibilidad educativa rural, que se define como el establecimiento $y$ desarrollo continuo de un conjunto de acciones educativas para alcanzar los niveles socioculturales indispensables para el desarrollo humano integral de la mayoría de la población rural. Una tarea perentoria es un posicionamiento epistemológico basado en una orientación $y$ un proceso de planificación crítica de los currículos educacionales en América Latina.

La crítica certera y profunda que ha realizado Magendzo, en el análisis crítico de la estructura del currículo centrado en las disciplinas de estudio, pone en evidencia la urgente necesidad de asumir un nuevo camino que permita superar la reproducción cultural que propicia ese tipo de enfoque curricular. La superación de los códigos dominantes subyacentes en el currículo academicista, herederos de la formación colonial y presentes a lo largo del proceso de configuración de los sistemas nacionales educativos en América Latina.
Se considera, desde esta visión crítica, que la superación del currículo académico prevaleciente en los sistemas educativos ha sido, sigue siendo y será una de las principales tareas de resistencia educativa en América Latina. Especialmente, por poseer un carácter excluyente, desde el punto de vista sociocultural, para amplios segmentos de la población estudiantil de nuestros países $y$ de forma muy acentuada en las zonas rurales. La gran paradoja es, como lo ha explicado Magendzo (1986), que en los mismos planes de formación de los y las docentes rurales que pretenden tener una orientación crítica, se asume un diseño y una práctica pedagógica tradicional academicista. Es una tendencia generalizada en el mundo académico, la incongruencia entre las asunciones ideológicas y teóricas y las realizaciones prácticas que supuestamente se derivan de ellas. Aunque racionalmente asumimos una posición ideológica en cualquier ámbito, la realidad es que muchas veces en la práctica pedagógica concreta se niega esa asunción. Esto conlleva implicaciones negativas para alcanzar resultados positivos, en el marco de un compromiso educativo emancipador y contestatario, frente a toda tendencia educativa deshumanizante y hegemónica.

\section{FCFD: POSICIONAMIENTO EPISTEMOLÓGICO CRÍTICO Y EL CURRÍCULO ORIENTADO AL DESARROLLO HUMANO INTEGRAL (CODHI)}

Se ha puesto en evidencia la necesidad de promover en la formación docente, una competencia básica: la capacidad de asumir un posicionamiento epistemológico congruente entre la visión crítica educativa y la práctica pedagógica. En el ámbito curricular, esta acción requiere de asumir un enfoque curricular crítico que coloque la persona humana y su desarrollo integral como centro de la actividad pedagógica.

El conocimiento a profundidad y el dominio práctico del Currículo Orientado al Desarrollo Humano Integral (CODHI), desarrollado por Ángel Villarini Jusino, constituye, como ya se indicó, una valiosa contribución 
para asumir el desarrollo de las competencias ${ }^{7}$ personales formativas. En el ámbito de formación de los y las docentes rurales y de la población estudiantil rural, su aplicación adquiere una trascendencia especial, por sus fuentes $y$ fundamentos curriculares constructivistas $y$ humanistas, plenamente coincidentes a nivel epistemológico con las propuestas para los planes de formación de los y las docentes rurales. Se trata de aportar las competencias que contribuyan a enriquecer el perfil de dichos docentes. Cabe hacer la aclaración, por el prejuicio que comúnmente existe respecto al concepto de competencia por su aplicación en el campo del mundo laboral y empresarial, que en el contexto en que se sitúa adquiere un significado diferente. Como lo aclara Jonnaert (2002), el concepto de competencia no es incompatible con un paradigma socioconstructivista de construcción y de desarrollo de conocimientos y de competencias. Tanto el desarrollo de conocimientos y de competencias, observa Jonnaert, se construyen en situación y en estrecha relación; asimismo, en interacción, se realizan paralela y complementariamente. Además, destaca el carácter más global de la competencia, puesto que desde una visión socioconstructivista, recurre a otros recursos. Una competencia desde el socioconstructivismo, al igual que los conocimientos 1) se construye; 2) está situada; 3) es reflexiva y 4) es temporalmente viable ${ }^{8}$.

$7 \quad$ Cabe hacer la aclaración que el uso del concepto de competencia, formulado por Villarini, está lejos de asumirse desde del concepto de competencia basado, desde una perspectiva reduccionista, en las competencias laborales en el campo de la producción industrial —o cualquiera de las otras concreciones positivistas - que únicamente tienen como intención la eficiencia y eficacia productiva propios de los modelos de gestión y los modelos de producción, en el marco de la filosofía y estrategia empresarial denominada "calidad total".

Las funciones específicas que cumplen las competencias a partir de esta caracterización son: 1) movilizar y 2) coordinar una serie de recursos variados, cognitivos, afectivos, sociales, contextuales, etc.; 3) tratar exitosamente las diferentes tareas que solicita una situación dada y 4) verificar la pertinencia social de los resultados de los tratamientos efectuados en una situación (Jonnaert, 2002: 18).
Respecto del CODHI, Villarini explica:

El currículo orientado al desarrollo humano integral es un plan estratégico de estudio que organiza el contenido y actividades de enseñanza en una secuencia integrada y progresiva, a partir del potencial biopsicosocial del estudiante, para suscitar experiencias de aprendizaje auténtico que contribuyan al desarrollo de competencias humanas (habilidades generales) como base de su formación integral (Villarini, 1997: 5).

El CODHI se elabora a partir de una perspectiva filosófica, biopsicosocial y socio-política de carácter humanista, constructivista, social y liberadora y como lo señala Villarini, se orienta al desarrollo de diez áreas de competencia o habilidades humanas generales que se constituyen en los elementos vertebradores de la formación integral del estudiante.

El CODHI se orienta -explica Villarini (1997: 5) — al desarrollo de diez áreas de competencias (habilidades) humanas generales que definen la formación integral del estudiante, a saber: (1) Pensamiento sistemático, creativo y crítico. (2) Comunicación significativa y creativa. (3) Interacción social efectiva. (4) Autoestima personal y cognoscitiva. (5) Conciencia ética. (6) Sensibilidad estética. (7) Conciencia ambiental y salubrista. (8) Conciencia histórica y cívica. (9) Habilidad psicomotora para la recreación y el trabajo. (10) Sentido de trascendencia.

Un aspecto importante de esta propuesta curricular es que es aplicable a un programa vocacional o profesional en virtud de que las competencias humanas generales se integran con las profesionales —observa Villarini (1997: 6) - para originar un currículo de "desarrollo humano profesional". El CODHI es concebido como un "arte" que depende más de las habilidades humanas generales del profesional que de los conocimientos científicos y técnicos que posea. En sus palabras: 
Sin descuidar la enseñanza de un riguroso contenido científico y técnico, el currículo de desarrollo humano profesional busca fomentar el desarrollo de competencias profesionales generales que capaciten para una práctica autónoma $y$ de excelencia $y$ responsabilidad ética $y$ social en el servicio (1997: 6).

Ciertamente, la utilización de esta propuesta curricular, con su opción por un aprendizaje auténtico ${ }^{9}$, en los planes de formación de docentes rurales constituye un excelente instrumento teórico-metodológico, para un desarrollo curricular que promueva el desarrollo humano integral de la población estudiantil del medio rural latinoamericano.

\subsection{LA NUEVA RURALIDAD Y LA FORMACIÓN CONTINUA Y EDUCACIÓN A LO LARGO DE LA VIDA DE LAS Y LOS EDUCADORES RURALES}

Para garantizar la sostenibilidad educativa rural es imperativo un programa de formación continua para los educadores rurales, in situ (formación en servicio), basado en una metodología de investigación-acción y centrado en una perspectiva de liderazgo comunitario, para que obtengan las competencias humanas $y$ profesionales que les permitan conceptualizar críticamente, su propia praxis educativa e integrarse como educadores sociales a la dinámica de la vida en las comunidades rurales. Desde esta visión, la formación continua entendida como una actitud permanente de actualización crítica, en general, de los conocimientos y

$9 \quad$ Villarini define el aprendizaje auténtico de esta manera: "En el aprendizaje auténtico el estudiante pasa por un proceso que: (1) parte de sus necesidades y capacidades; (2) asume los objetivos del proceso de enseñanza, al reconocer sus fortalezas y limitaciones con relación a los mismos; (3) se involucra en una actividad de estudio; (4) que lo lleva a interactuar con los otros educandos y educadores y (5) a tener una experiencia educativa. Cuando el estudiante (6) reflexiona sobre su experiencia $y$ se percata de que ya no es el mismo, de que ahora comprende o domina un aspecto nuevo de la realidad, que ha adquirido una capacidad o poder, se completa el proceso de aprendizaje y se promueve el desarrollo humano" (1997: 8-9) . competencias de la teoría y práctica educativa, en particular, pedagógica, es indispensable que esté incorporada en los planes de formación de las y los educadores rurales.

Esta acción debe complementarse con una acción concertada por los Ministerios de Educación Pública y las Facultades de Educación de las universidades públicas y estatales, en acciones tales como:

$\diamond \quad$ Formulación de un plan nacional de formación continua para los educadores rurales: MEP y universidades.

$\diamond \quad$ Integración con otros profesionales de otras instituciones $y$ organizaciones de la sociedad civil que trabajan en el medio rural.

$\diamond \quad$ Estímulos profesionales $y$ de formación en servicio (elevación de las competencias).

\section{$\diamond \quad F C F D:$ FORMACIÓN CONTINUA Y EDUCACIÓN A LO LARGO DE LA VIDA}

La adquisición de la cultura de la formación continua debe estar en la base de la formación de las y los docentes rurales; asimismo, el mejoramiento continuo del docente rural debe ser una práctica permanente. En el Informe "La educación encierra un tesoro" se menciona el hecho de que, el adelanto científico y tecnológico y la transformación del mundo productivo en términos de competitividad, ha determinado que los saberes y las técnicas adquiridas en la formación inicial por cada individuo, pierden rápidamente vigencia, por lo que se constituye en un asunto de capital importancia, la capacitación profesional permanente. Empero, la formación continua debe trascender la visión profesional y académica, para incorporar un concepto de alcance mayor, como lo es el de educación a lo largo de la vida. Esa trascendencia significa que el trabajo y los aprendizajes para realizarlo se combinan con una formación a lo largo de las diversas etapas del individuo, considerando el ejercicio de una ciudadanía activa (Delors et ál., 1996: 113).

Los planes de formación docente para la educación rural deben enriquecerse de esta 
visión educativa e incorporar el concepto de educación a lo largo de la vida, como un elemento central del proceso formativo de las $y$ los docentes de todos lo niveles y modalidades del subsistema educativo del mundo rural. Esto adquiere una significación especial, al considerar los cambios e influencia que devienen de la sociedad del conocimiento, que trasciende a la cultura rural, según las tendencias de la nueva ruralidad. Solo con una acción formativa permanente, las y los docentes rurales podrán enriquecer $y$ fortalecer las competencias para el desarrollo humano integral de la mayoría de la población rural y al mismo tiempo, transmitir a sus estudiantes esta visión para que sea asumida como uno de los aprendizajes más importantes en cualquiera de los niveles del sistema educativo o en cualquier experiencia de la educación no formal.

En síntesis, se considera que el concepto de educación a lo largo de la vida debe ser asimilado en la cultura pedagógica de las $y$ los docentes rurales. En particular, el sentido que le confiere a cada persona, la capacidad de dirigir su destino y compartirlo con sus semejantes, en un mundo en que la aceleración del cambio en el marco de la mundialización tiende a modificar la relación entre los hombres y las mujeres con el espacio y el tiempo.

\subsection{EDUCACIÓN INTERCULTURAL PARA LA DIVERSIDAD SOCIOCULTURAL DE LOS TERRITORIOS RURALES}

Según se ha indicado anteriormente, la emergencia de nuevos patrones de vida que los cambios socioculturales de la nueva ruralidad han provocado, representa uno de los aspectos neurálgicos que enfrenta la educación rural. En efecto, una de las más conspicuas tendencias de la nueva ruralidad bajo el enfoque territorial, son las diversas manifestaciones de la multiculturalidad y la interculturalidad. Estos procesos de la visión social del enfoque territorial plantean, en efecto, uno de los retos educativos $y$ pedagógicos cardinales en el mundo rural latinoamericano. La especialista en educación intercultural Teresa Aguado (1991a) advierte que, existe una tendencia a confundir ambos términos. Puntualiza que en los ámbitos de la
Educación, la Sociología y la Política se utilizan términos de manera indiscriminada que incorporan a la raíz "cultural" los prefijos "multi", "inter", "pluri" y "trans". Teresa Aguado (1991b), con respecto al término multicultural, expresa que está referido al hecho de que, muchos grupos o individuos pertenecientes a diferentes culturas vivan juntos en la misma sociedad, mientras que el término intercultural añade a lo anterior el hecho de que, los individuos o grupos diversos se interrelacionan, se enriquecen mutuamente y son conscientes de su interdependencia ${ }^{10}$. En correspondencia con estas tendencias, subraya el hecho de que el concepto de educación intercultural está referido a una tendencia reformadora de la práctica educativa $y$ variada en sus metas; en consecuencia, responde a la diversidad resultante de la confrontación y convivencia de diferentes grupos étni$\cos y$ culturales en una determinada sociedad.

\section{↔ FCFD: INTERCULTURALISMO Y EDUCACIÓN INTERCULTURAL}

Gil Jaurena define la educación intercultural como un:

... enfoque educativo holístico e inclusivo que, partiendo del respeto $y$ la valoración

10 En respuesta a esta confusión de nociones señala que para superarla a finales de los setenta, el Consejo de Europa planteó una definición para cada término. Al respecto apunta: "Con el término multicultural se define la situación de las sociedades, grupos o entidades sociales en las que muchos grupos o individuos que pertenecen a diferentes culturas viven juntos, cualquiera que sea el estilo de vida elegido. Pluricultural es casi un sinónimo, indica simplemente la existencia de una situación particular. Se utiliza en las mismas circunstancias, pero en lugar de subrayar la existencia de un amplio número de culturas en contacto, se resalta únicamente su pluralidad. Transcultural implica un movimiento, indica el paso de una situación cultural a otra. Finalmente, intercultural no se limita a describir una situación particular, sino que define un enfoque, procedimiento, proceso dinámico de naturaleza social en el que los participantes son positivamente impulsados a ser conscientes de su interdependencia y es también, una filosofía, política y pensamiento que sistematiza tal enfoque" (Aguado, 1991, citando a Leurin, 1987; la cursiva es propia). 
de la diversidad cultural, busca la reforma de la escuela como totalidad para incrementar la equidad educativa, superar el racismo/discriminación/exclusión, favorecer la comunicación y competencia interculturales $y$ apoyar el cambio social según principios de justicia social (2002: 15).

Con base en esta definición, explica que se trata de un i) enfoque educativo que consiste en una manera de entender la educación como proceso continuo; ii) un enfoque holístico porque afecta integralmente todas las dimensiones de la educación (no solo el curriculum); iii) un enfoque inclusivo, en tanto es una educación, no solo de minorías étnicas o inmigrantes, sino de todos; iv) concibe la diversidad como un valor; $v$ ) persigue reformar la escuela para obtener una educación de calidad $y$ vi) tiene cuatro objetivos fundamentales: equidad, antirracismo, competencia intercultural, transformación social.

La educación rural debe atender específicamente, la diversidad sociocultural y estructural de las regiones rurales en que conviven los grupos humanos étnicos diversos que integran esos espacios rurales. Por lo tanto, debe asumir una dimensión inclusiva, intercultural, de género $y$ de acceso a las tecnologías de la información y comunicación.

La formación docente rural debe contemplar estos aspectos para desarrollar una práctica educativa que responda a los retos de la nueva ruralidad.

$\diamond \quad$ Importancia del fundamento intercultural y del enfoque pedagógico intercultural de los planes y programas de estudio.

$\diamond \quad$ Tematización curricular de la riqueza y diversidad multicultural e intercultural.

$\diamond \quad$ Educación con ejes transversales en valores socioculturales de los grupos étnicos que conviven en los espacios geográficos rurales.

$\diamond \quad$ La formación docente debe poseer un fuerte componente formativo en el campo emergente de la educación intercultural para atender la diversidad sociocultural y étnica de las comunidades rurales.

\subsection{PARTICIPACIÓN ORGANIZADA Y DEMOCRÁTICA DE LA ESCUELA RURAL CON LOS DIVERSOS ACTORES DE LA SOCIEDAD CIVIL RURAL}

Uno de los efectos negativos que el cambio de la nueva ruralidad ha traído consigo en las comunidades rurales es que, estas han mostrado un debilitamiento en las solidaridades colectivas, como resultado de la desintegración territorial y social. Esta tendencia se ha producido en muchos casos debido a los desplazamientos forzosos poblacionales por la violencia (como el caso de Colombia) o por los fenómenos naturales en algunos países latinoamericanos. El nuevo modelo ha provocado nuevas formas de acceso a la tierra $y$ ha mostrado un mayor protagonismo del crecimiento de capital, en virtud de la incorporación de la propiedad financiera en el medio rural y en las actividades agropecuarias. Problemas de esta naturaleza producen un cambio importante en las demandas colectivas de lo rural que trascienden la tensión por la propiedad. La población rural en muchos casos reclama servicios básicos y mecanismos de participación (Pérez, 2000: 22).

Para canalizar adecuadamente dichas demandas sociales, ante las instancias gubernamentales, se requiere de un alto grado de participación organizada por parte de la ciudadanía. Pero esto, a su vez, impone el reto de que la educación contribuya desarrollando la conciencia y las actitudes que favorezcan en el medio rural la participación organizada y democrática de los diversos actores de la sociedad civil rural (principalmente los actores educativos: estudiantes, educadores, padres, autoridades de los ministerios de educación pública, líderes comunales, etc.). Esto implica que los currículos estén estrechamente vinculados y respondan a los principales objetivos estratégicos del desarrollo rural, en su particular condición históricaestructural y coyuntural. Por consiguiente, una rigurosa definición de la estrategia de acción para promover la participación ciudadana $y$ de 
los diversos actores sociales de los territorios rurales debe considerar entre otros aspectos:

$\diamond \quad$ La realidad histórico-estructural teniendo en cuenta aspectos tales como: las dimensiones sociales, económicas, políticas, culturales y medioambientales de los territorios rurales.

$\diamond \quad$ Una visión concertada del cambio educativo (democrático) para las zonas rurales, tanto reformas como innovaciones, que tome en cuenta los principales actores de la sociedad civil rural.

$\diamond \quad$ Una fundamentación en un análisis a profundidad de las particularidades socioculturales de las zonas rurales de nuestros países: visión del mundo de los actores sociales, marcos de representación simbólica, procesos de construcción de significados socioculturales, principales patrones de la acción comunicativa, etc.

Solo con el conocimiento de las particularidades estructurales de los territorios rurales adquiridos, mediante los precitados elementos de diagnóstico, podrá situarse una clara concepción del papel de los ciudadanos del territorio rural en la dinámica sociopolítica.

\section{$\diamond \quad$ FCFD: FORMACIÓN CIUDADANA Y PARTICIPACIÓN DEMOCRÁTICA}

La formación ciudadana debe trascender la simple adquisición de conocimientos sobre temas cívicos. En esta dirección, debe propiciar el desarrollo de una moral cívica (Cortina, 1999), una conciencia social solidaria y de habilidades $y$ valores que permitan al estudiante participar, incidir y mejorar la vida de su grupo, su comunidad y su país. Como lo expresa Adela Cortina, construir una sociedad con vigor ético requiere de una formación en valores morales en los que se cree y deberían realizarse a través de la escuela, la familia, el grupo de edad y/o los medios de comunicación (1999: 95).

La centralidad de la formación ciudadana para la participación democrática está más que justificada en América Latina, con una historia tan marcada por la violación al Estado de derecho y los principios democráticos. Esta formación implica, además, desarrollar su capacidad para la reflexión y el cuestionamiento de la realidad sociopolítica del medio rural y de la sociedad en su conjunto. En consecuencia, es preciso incluir en los ejes temáticos de los planes de estudio de los educadores rurales, una sólida formación en los temas relacionados con la formación ciudadana y la participación democrática desde una perspectiva crítica y basada en la ética de la solidaridad social y sus formas de organización. Esto no solo les capacitará para asumir los retos formativos de área curricular tan sensible, sino para que participen activa y críticamente en el contexto rural en que ejercen su magisterio educativo.

\section{REFERENCIAS BIBLIOGRÁFICAS}

Albanesi, Roxana y Preda, Graciela. "El enfoque territorial como propuesta de intervención para el desarrollo. Reflexiones desde una perspectiva latinoamericana”. La enseñanza del desarrollo rural. Enfoques y perspectivas. 2007.

Aguado Odina, Ma Teresa. "La educación intercultural: concepto, paradigmas y realizaciones". M ${ }^{\text {a }}$ Carmen Jiménez Fernández (coord.). Lecturas de Pedagogía Diferencial. Madrid: Dykinson, 1991a.

Aguado Odina, $\mathrm{M}^{\mathrm{a}}$ Teresa. "Lecturas de Pedagogía Diferencial”. Seminario de Educación Multicultural. Veracruz. $\mathrm{M}^{\mathrm{a}}$. del Carmen Jiménez Fernández (coord.). Madrid: Dykinson, 1991b. En: <www. cnice.mecd.es/interculturanet/archivos/ eintercultural.rtf>

Antonio Pérez y José María Caballero. La nueva ruralidad en Europa y su interés para América Latina. FAO-Banco Mundial, 2003.

Baquedano, Manuel. "¿Planetarización o globalización?”. Revista del Sur 89. Marzo 1999. En: <http://www. redtercermundo.org.uy/revista_del_sur/> 
Ceña, Felisa. "El desarrollo rural en sentido amplio". El Desarrollo Rural Andaluz a las Puertas del siglo XXI. Congresos y Jornadas 32. Andalucía, España. 1993.

Cortina, Adela. Los ciudadanos como protagonistas. Barcelona: Galaxia Gutemberg, 1999.

Cortina, Adela. La ética de la sociedad civil. Madrid: Editorial Anaya, 2000.

Giarracca, Norma (comp.). ¿Una nueva ruralidad en América Latina? Buenos Aires: CLACSO, 2001.

Gil Jaurena, Inés. "La educación intercultural en la enseñanza obligatoria: una guía para su evaluación y desarrollo". Trabajo de investigación (inédito). 2002.

González González, Ma Teresa y Escudero Muñoz, Juan Manuel. Innovación educativa: teoría y procesos de desarrollo. Barcelona: Editorial Humanitas, 1987.

Delors, Jacques et ál. "La educación encierra un tesoro". Informe a la UNESCO de la Comisión Internacional sobre la educación para el siglo XXI. Presidida por Jacques Delors. Madrid: Santillana Ediciones UNESCO, 1996.

Instituto Interamericano de Ciencias Agrícolas (IICA). "Nueva ruralidad. El desarrollo rural sostenible en el marco de una nueva lectura de la ruralidad". Serie: Documentos conceptuales. Panamá: Desarrollo rural sostenible, CIDER. 2000.

Jonnaert, Ph. Competencias y socioconstructivismo. Nuevas referencias para los programas de estudios. Montreal: UQÀM, 2002. En: <http:// www.riic.unam.mx/01/02_Biblio/ d o c / C o mpetencias $\% 20$ y $\% 20$ socioconstructivismo\%20JONAERT.pdf>

Lacki, Polan. "La escuela rural debe formar solucionadores de problemas". Revista Perspectivas Rurales. Nueva ruralidad en América Latina 4 (2). Heredia: Universidad Nacional de Costa Rica, 2000.

Llambí Insua, Luis y Pérez Correa, Edelmira. "Nuevas ruralidades y viejos campesinismos". Agenda para una nueva sociología rural Latinoamericana. Bogotá, Colombia: Cuadernos Des. Rural, 2007.
Magendzo, Abraham. "Currículo y cultura en América Latina”. Programa Interdisciplinario de Investigación en Educación. 1986.

Martínez Otero, V. "Cultura escolar y mejora de la educación”. En: <http://lasalle.edu.mx/ docs/dip1/cultura_escolar_mejora.pdf >

Méndez Puga, Ana María. "Formación de educadores (as) y educación rural: reflexiones y propuestas desde una reconceptualización de la educación básica”. Revista Digital eRural, Educación, Cultura y Desarrollo Rural 1. Julio 2003. En: <http://educación.upa.cl/ revistaerural/erural.htm>

Mendoza, Carmen Cecilia. "Nueva ruralidad y educación: miradas alternativas". Reenseñanza 9. 2004.

Miranda Camacho, Guillermo. "Hacia una visión hermenéutica crítica de la política educativa”. Revista de Ciencias Sociales 111-112 (I-II). Universidad de Costa Rica, 2006.

Niño Carrillo, Lucy A. "Estrategias de desarrollo rural para una nueva ruralidad" Conferencia Inaugural La nueva ruralidad en América Latina. Maestría en Desarrollo Rural 20 años. Tomo I. Colombia: Pontificia Universidad Católica, 2001.

OEA-ME. Informe Final del Seminario Interamericano sobre Problemas de la Educación Rural. Venezuela: Rubio, 1971. Organización de las Naciones Unidas para la Agricultura y la Alimentación (FAO). "Educación para la población rural". 2009. En: <http://www.fao.org/sd/erp/ index_es.htm>

Peralta Espinosa, M. Victoria. Currículos educacionales en América Latina. Su pertinencia cultural. Chile: Editorial Andrés Bello, 1996.

Pérez, Antonio y Caballero, José María. La nueva ruralidad en Europa y su interés para América Latina. Roma, Italia: FAO, 2003.

Pérez, Edelmira. "Hacia una nueva visión de lo rural”. Giarracca, Norma (comp.). ¿Una nueva ruralidad en América Latina? Buenos Aires: CLACSO, 2001. 
Pérez Correa, E. et ál. (ed.). Memorias del Seminario Internacional La Nueva Ruralidad en América Latina (Dos volúmenes). Bogotá: Pontificia Universidad Javeriana-Facultad de Estudios Ambientales y Sociales, 2001.

Pérez Gómez, Ángel I. La cultura escolar en la sociedad neoliberal. Madrid: Ediciones Morata, 1999.

Plaza, Orlando. Desarrollo rural: enfoques y métodos alternativos. Lima: Pontificia Universidad Católica del Perú, 1998.

Solís Araya, Clara. "El desarrollo rural sostenible en el marco de una nueva lectura de la ruralidad". E. Pérez Correa et ál. (ed.). Memorias del Seminario Internacional La Nueva Ruralidad en América Latina. Bogotá: Pontificia Universidad JaverianaFacultad de Estudios Ambientales y Sociales, 2001.

Tejo, Pedro. "La pobreza rural una preocupación permanente en el pensamiento de la CEPAL". Serie de Desarrollo Productivo. Chile: CEPAL, Naciones Unidas. 2000.

Teubal, Miguel. "Globalización y una nueva ruralidad en América Latina”. Giarracca, Norma (comp.). ¿Una nueva ruralidad en América Latina? Buenos Aires: ClACSO, 2001.

Trejos, Rafael A. "Nueva ruralidad. Temas emergentes, nuevos, condicionantes y viejos problemas". Revista Perspectivas Rurales 4 (2). Heredia: Universidad Nacional de Costa Rica, Maestría en Desarrollo Rural. 2000.

Villarini Jusino, Ángel. El currículo orientado al desarrollo humano integral. San Juan, Puerto Rico: Biblioteca del Pensamiento Crítico, 1997.

Fecha de ingreso: 01/11/2010

Fecha de aprobación: 07/11/2010 
